\title{
Composition and biological degradability of lignin modified transgenic plants
}

\author{
MA Bernard Vailhé, JM Besle, A Cornu, MP Maillot
}

\author{
INRA, Unité Digestion Microbienne, Theix, 63122 St-Genès-Champanelle, France
}

The influence of lignin quality on cell wall degradation was studied using, as model plants, control (C) and transgenic (AS) tobacco plants (cv Samson), on which the cinnamyl alcohol dehydrogenase (CAD) was inhibited using the antisense strategy (Halpin et al, 1994, Plant J, 6, 339-350).

The samples were 14 week-old stems of line 40 (low CAD inhibition) and lines 48 and 50 (high CAD inhibition). They were ground to pass through a $500 \mu \mathrm{m}$ sieve and the particles $<100 \mu \mathrm{m}$ were discarded. The biological degradability of the remaining was measured in situ in the rumen or with cellulase (Rexen, 1977, Anim Feed Sci Technol, 2, 205-218) and analysed before and after in situ rumen incubation (48 h). Cell wall residues (CWRs) from the initial dry matter (DM) and lignin content were determined according to Jarrige (1961, Ann Biol Anim Biophys, 1, 163-212). Esterified phenolic acids and lignin uncondensed monomers (nitrobenzene oxidation method) were analysed as described by Mosoni et al (1993, J Agr Food Chem, 41, 1349-1354).
The CWRs and lignin content varied slightly with the lines but not between controls and AS counterparts. In comparison with controls, AS had a slightly lower syringyl to guaiacyl ratio for lines 48 and 50 but not for line 40 . No esterified phenolic acid was detected. The genetic modification produced an increase of in situ CWR disappearances (ISCWRD) of 3.3 and 6.3 percent units for lines 48 and 50 , but not for line 40 . The cellulase solubilities (CCWRS) followed the same trends : increase of 2.4 and 7.6 percent units for the AS lines 48 and 50 respectively.

The compositions of the fermented residues were not different between the control and the AS samples. The increase of ISCWRD was due to a greater disappearance of all components in the AS stem-CWR than in the control samples.

The ISCWRD was improved only in the samples with the highest $C A D$ inhibition while the initial CWR composition was unmodified. It is suggested that high CAD inhibition did not change lignin content but lignin structure, which in turn allowed a greater degradability of the cell wall.

\begin{tabular}{lcccccc}
\hline line & \multicolumn{2}{c}{40} & \multicolumn{2}{c}{48} & \multicolumn{2}{c}{50} \\
& C & AS & C & AS & C & AS \\
CWR (\% DM) & 76.7 & 76.7 & 76.7 & 71.2 & 72.3 & 72.6 \\
Lignin (\% CWR) & 14.8 & 14.7 & 15.6 & 16.0 & 15.5 & 15.4 \\
Syringyl / guaiacyl & 0.75 & 0.75 & 0.38 & 0.26 & 0.75 & 0.67 \\
ISCWRD & 22.6 & 20.0 & 18.7 & 22.0 & 14.0 & 20.3 \\
CCWRS & 29.1 & 28.9 & 15.8 & 18.2 & 17.3 & 24.9 \\
\hline
\end{tabular}

The coefficients of variation were lower than $2,3,10,5$ and $3 \%$ for CWR, lignin, syringyl/guaiacyl, ISCWRD and CCWRS determinations respectively. 